\title{
ANNOTATION
}

\section{The Glasgow Clinic for Certification of the Blind}

An important paper by C. M. Smith and John Marshall appeared in the Lancet for July 9 and 16,1932, giving details of the causes of blindness in 1,460 cases. It is to be hoped that all ophthalmic surgeons as well as all those who are interested in the problem of blindness will study the original. It is not possible, within the limits of an annotation, to give a full abstract of such a mass of statistical information as is here presented; but an attempt is made to skim the cream in the hope that all will turn to the original.

Freeland Fergus, who was the principal mover in this matter, may well feel proud of the results which have been recorded to date. Prior to the year 1925, candidates for admission to the blind register were only in exceptional instances certified by, an ophthalmic surgeon. In 1926, the first report by Freeland Fergus and Chalmers, dealt with a special survey of the adult blind population of Glasgow, and was noticed in our columns (Vol. X, p. 343). The recommendation that all persons seeking admission to the register of the blind should be examined by a board of ophthalmic surgeons bore fruit, and in 1929 a certifying clinic was established by the Joint Committee for the South-West of Scotland for the administration of the Blind Persons Act, 1920.

This clinic is a regional one administered by the Joint Committee, under the control of the Medical Officer of Health for Glasgow. It has already served as a model on which similar clinics have been fashioned. The region served contains a population of 2,700,000, of whom 4,200 are on the blind register. Four ophthalmic surgeons attend two sittings a week, at which about a dozen cases are examined. The surgeons work in pairs, each pair constituting a board. Their names are A. L. McMillan, H. Walker, J. A. Mortimer and John Marshall. It should be noted that the clinic is a certifying one; in many cases treatment is advised, but no treatment other than the prescribing of glasses is carried out. With regard to the source of candidates figures are available for one year only, 1931. In that year 246 applicants were examined and 109 found to be blind. In the same year at the request of certain public committees 252 cases were examined and 195 of them found to be blind. In the same year 74 candidates for training at the Royal Glasgow Asylum for the Blind were examined, of whom 30 were found to be blind. The outdoor mission to the blind sends a large number of cases to the clinic; in the year in question 166 cases, of whom 91 were blind, came from this source. The Transport Committee grants free facilities for travel in Glasgow to those blind who are 
certified by the clinic. In 1931,64 cases were examined on behalf of this committee and 45 certified as blind. The only hole in the net to date occurs in connection with the certification of blind children of school age, as, under the act, such cases are the responsibility of the education board. In view of the recommendation of the joint memorandum on medical certification and standard of blindness arrangements have been made in Glasgow for the certification of all blind children of school age before admission to a blind school is approved; when these arrangements are completed the clinic will be a certifying unit for all purposes. Applicants unable to travel are examined at their own homes. Since the clinic opened in August, 1929, to the end of the year 1931, 249 such cases have been examined, of whom 86 per cent. have been found to be blind.

The standard of blindness adopted is that advised by the Ophthalmological Section of the Royal Society of Medicine in July, 1915. With regard to the collection and analysis of data the "Hollerith" system has been found to be invaluable. This system has been in use in Glasgow for five years for routine departmental purposes. The card for blind certification is appended to the paper. The list of causes of blindness has been drawn up on the basis of prevention. Group I contains congenital and undeterminate causes which, in the present state of our knowledge, are not preventable; it includes myopia, glaucoma and cataract. Further subdivision gives the following six groups:- congenital and undetermined; infectious and toxic; traumatic and chemical ; systemic diseases; not ascertained definitely; and lastly, no defect. A satisfactory code has been evolved from the data of the first 1,500 blind cases certified. The code is a three figure one, the essential point being that the first two figures represent the principal eye defect and the last figure the complication or sequel. Under this code a case of choroido-retinal disease with interstitial keratitis is recorded as 075: 07 being the code figure for interstitial keratitis and 5 that for choroido-retinal disease. Emphasis is laid upon the care necessary in differentiating between primary and secondary cataract.

The importance of studying border-line cases is also emphasised and provision is made for re-examination of cases not considered to be blind.

Many statistical tables are given, much space being devoted to the actual causes of blindness in Tables 4 and 5 and examples of information obtained conclude this excellent piece of work. We trust that in congratulating Scotland on its pioneer work in this direction we have said enough to indicate the far reaching importance of the results here recorded. 